\title{
Enterprise education: learning through personal experience
}

\author{
Colin Jones
}

\begin{abstract}
This paper outlines the development of a reflective process through which student feelings are brought to the surface to advance their learning outcomes. A key notion in relation to the capacity of student development is the ability of students to alter their collective habits of thought and in turn the nature of the learning environment. The paper examines student reflection in the context of students' heightened awareness of self and their potential influence on their environment. The notion of 'surfacing feelings' is used to describe the outcome of individual and group reflection through which several parties become aware of the active reflections of individual students, thereby increasing the potential depth of overall reflection. Finally, the author considers the transferability of the ideas discussed to other educational contexts.
\end{abstract}

Keywords: self reflection; group reflection; student diversity; enterprise education

The author is with the Australian Innovation Research Centre, University of Tasmania, Private Bag 108, Hobart 7001, Australia. E-mail: Colin.Jones@utas.edu.au.

How can we be sure how much our students benefit from exposure to experiential educational processes? This paper seeks to address this question, using the voice of the student as evidence for its argument. The context for the discussion is the provision of enterprise education at both undergraduate and postgraduate levels. Enterprise education programmes have long been associated with experiential education processes and, furthermore, are increasingly catering for students from a wide variety of disciplines.

This increasing diversity creates a challenge for the enterprise educator in that students frequently report that the teaching methods employed seem loose or unstructured compared to those of other study programmes. However, in the context of this paper, an even greater challenge is faced by the students. The learning approach discussed here is based on the assumption that the curriculum is organized around the belief that what the students must learn relates first and foremost to what resides inside them. Central to the students' learning, in other words, is a sense of awareness of their capacity to manage risk, to rise to the various challenges and opportunities that life presents and to deal with important issues decisively.

Over the past six years a unique teaching framework in enterprise education has been evolving - a framework designed to create space for students to interact with a few core ideas in a way that is specific to themselves. This approach is based on the notion that, to comprehend and apply theoretical topics, students must develop a heightened sense of themselves so that the theory can be applied in their 'here and now'. A key tool is personal and group reflection. Incorporating the works of Tyler (1949) and Whitehead (1929), this paper will explain how a learning framework has been developed in which transformative learning experiences are commonplace. The next section summarizes the approach, hereinafter referred to as the 'hic et nunc framework'. 


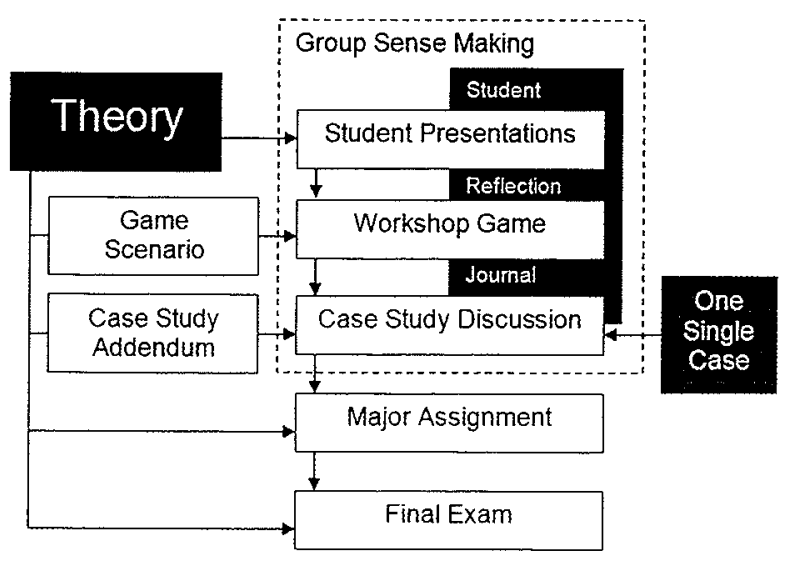

Figure 1. The hic et nunc learning and teaching framework.

\section{The teaching framework}

Taking its name from a literal translation into Latin of the term 'here and now', the hic et nunc framework encourages and enables each student to learn in his or her 'here and now' (Whitehead, 1929), thus accommodating the development of different interpretations of the required learning topics. A key factor in the learning process is the provision for continuous student reflection (Tyler, 1949) on the repeated learning activities that occur during and across fortnightly workshops.

Over time the learning activities have evolved to include games, case study discussions, workshop presentations and reflective diaries, all of which are tied to the (theoretical) topics introduced cumulatively throughout the workshops (see Jones, 2007, for a detailed discussion). The purpose of the learning activities developed and continually refined is to accelerate the 'process of changing the behaviour patterns ... [of the students] ... using behaviour in the broad sense to include thinking and feeling as well as overt action' (Tyler, 1949, pp 5-6). The configuration of the learning activities is illustrated in Figure 1.

The programme has two specific aims: to assist the student to make the journey to graduate entrepreneur and (more generally) to help the student develop the attributes of a 'reasonable adventurer'. Heath (1964) defines the reasonable adventurer as a graduate student capable of making his or her own opportunities for satisfaction - a disposition seen as a prerequisite for entrepreneurial behaviour. The hic et nunc processes are repetitive, and typically commence with the introduction of new theory that is applied by the students across the various learning activities - an essential assumption being that students can alter their habits of thought from one workshop to the next. Before proceeding to the main focus of the paper, it is necessary to consider this assumption in more detail.

\section{Modification of students' habits of thought}

The above argument rejects the view that student interaction in a particular learning environment will result in sorting by specific learning or skill traits according to the assessment procedures adopted. Rather, it is assumed that, regardless of the distribution of student learning outcomes, the learning environment will not remain unaltered by the interaction. It is assumed that change internal to the student (that is, change to habits of thought) and its behavioural expression (phenotypic expression) is possible due to the interaction with a learning environment. The process begins with interaction between the student as individual and as group member in the learning environment.

During this first period, each student and his or her group will engage in various learning activities, which will be assessed using both summative and formative feedback. During the assessment process, the fitness of the routines used individually by each student and by his or her group will be assessed. These routines represent the activity systems responsible for phenotypic expression (for example, the content and context of the student's/group's performance and associated identity projected for the consumption of the assessors).

Consequently, the habits of thought of each student are subject to differential selection (for or against) on the basis of their contribution to the phenotypic expression of the individual and/or the group. A combination of freedom (Whitehead, 1929) and reflection (Tyler, 1949) then provides the means through which the group, and therefore individuals, may alter behaviours via a shift in their collective and separate habits of thought. This process of group and individual change is facilitated in the first instance by the summative information received (the grading) and then by the formative information that relates to both the negative and the positive aspects of the group's/ individual's performance. Therefore, the various assessment procedures act as selection mechanisms.

This process of generating both summative and formative assessment fulfils two important functions. First, the summative feedback provides an indication of the immediate fitness of the group's/individual's performance vis-à-vis the assessment criteria at a particular time. Second, the formative feedback provides information through which future change is possible. So the 'difference between them is that at some point the judgement has to be final' (Biggs, 2003, 
p 142). The composition of the interacting elements is also influenced by the internally held perceptions within the group that may be altered to produce many different outcomes. So, three forms of inheritance are possible and likely throughout the process:

- First, students' habits of thought (derived from their habits of life) are subject to revision as they determine what mental capabilities will best assist their progress. Altered habits of thought are then inherited (or transferred) from one learning environment (workshop) to the next through a student's individual behaviour or contribution to the group.

- Second, those aspects of the modified phenotypic expression (deemed to be favourable) and related to any changed habits of thought, are inherited by the groups from one learning environment to the next.

- Third, and perhaps most importantly, the behaviour of the individuals and groups has the potential to alter the nature of the future interaction between the learning environment and all the entities to be assessed. This is the central thesis of the 'niche construction' concept (Odling-Smee et al, 2003); it provides a means for students to alter or at least to place pressure on their learning environment within their time and space.

The discussion now turns to the important role of reflection throughout this process.

\section{Bringing the invisible to life}

Reflection makes visible the learning process occurring through the series of repeated experiential exercises that comprise the hic et nunc framework. Two forms of reflection are used throughout the educational process individual and group.

\section{Individual reflection}

The process of reflection is considered a critical element of the hic et nunc framework because 'learning takes place through the reactions he [or she] makes to the environment in which he [or she] is placed' (Tyler, 1949, p 63). Therefore, students' reflection on their participation in presentations, games and case study discussions is strongly encouraged. This is facilitated through a journal entry shortly after each workshop.

The reflection journal provides students with an opportunity to pause and reflect on how they feel about their contribution and the outcomes they have achieved in the various learning activities incorporated into the workshops. How well are they doing in the development of a successful strategy for the workshop game? How effectively are they participating in the case study discussion? Students are encouraged to consider what they have learned about themselves in the period between one workshop to the next. As the semester progresses, they are encouraged to engage in metareflection and consider how they have altered their approach and attitudes. This is a vital process that allows the students to take stock of their behaviour and consider what personal changes are required to improve or maintain their individual outcomes.

\section{Group reflection}

Recently, the hic et nunc framework (Figure 1) has been supplemented by the addition of another reflective exercise. The Group Sense Making exercise allows a deeper appreciation not only of personal feelings, but also of the feelings of other students in the class. A 'Situation Statement' is developed by the educator and distributed to the students for consideration - the statement is designed to elicit deep reflection about a specific social situation. The process is completed in four phases:

- Phase 1: The students identify and record their personal feelings about the Situation Statement. It is likely that they will have more than one feeling about it. Conflicting feelings and/or those that change over time should be noted. It is important that they do not note only assumed feelings, but also their actual feelings.

- Phase 2: The students (as a group) attempt to make sense of the context in the Situation Statement, using the perspectives of all the involved group members. This analysis may incorporate an exploration of personal beliefs, dispositions, experiences and attitudes.

- Phase 3: Each individual student now attempts to validate his or her analysis of the situation by asking for feedback from other (external) participants, peers, etc. In other words, the meaning attributed to the situation is confirmed by reference to the ideas and perspectives of others and/or through personal reflection on experiences.

- Phase 4: Each student indicates how reflection on the situation has influenced his or her approach to and/or perspective on this specific issue. Any shift in values, beliefs and attitudes is also noted.

Before considering how both single and group reflection processes are reconcilable to the aim of the programme (to develop the 'reasonable adventurer') and other established frameworks of reflective practice (for example, Kolb, 1984), it may be useful to allow the students themselves to speak. 


\section{The student voice}

The following are representative comments of students currently using both forms of reflective practice.

'I would say that the reflection exercises allowed me to see from a third person perspective my beliefs and attitudes. In relation to personal learning, this allowed me to easily criticize my learning patterns, and realize what needs to be fixed. In relation to group behavior, it allowed me to see what others might think of my behavior.'

'The reflection journals helped me consolidate what my strengths and areas for improvement were in reference to the course. The group situation statements were beneficial. They helped us to work in groups and effectively convey our feelings and ideas whilst enabling our entrepreneurial capacity.'

'After those experiential learning exercises I gain great insight into myself from the group sense making process. I have found it to be insightful, clarifying and helpful for me personally. I imagine that it will not only be me who benefits from this reflection exercise, but the lecturer will also gain a greater understanding of my personal learning outcomes than if I didn't complete the reflection.'

'From my experience the group sense making helped me to broaden my view of the subject. For example, after reading the other members of my group's phase one, I had other perspectives I had not thought of but still either agreed with or could understand where they were coming from. Also, if what I had written in my phase one was echoed by other members of my group, then I felt more confident that I was on the right track. I think the reflections also give the educator valuable insight into how the student is feeling and how they perceive their learning to be progressing.'

'The use of reflective learning has allowed for a heightened personal learning experience. It requires a more deep level of thought on self which makes the student more aware of how they are going and to look both more critically at the work completed as well as the positive achievement that has been had not in terms of marks but in a more personal way.'

These comments highlight the genuine benefits to both student and educator. Rather than merely allowing the student to reflect, the provision of group sense making allows multiple perspectives to be shared by students and the educator. Given the learner-centred nature of the hic et nunc framework, the insights thus gained are invaluable to the facilitator. A key driver in this context is the presence of vulnerability.

\section{Vulnerability}

According to Parker (1997, p 17), when we as educators despair, teaching may become a 'daily exercise in vulnerability'. Consequently, teachers may disconnect themselves from their students, and even their subjects, to reduce their vulnerability. They may thus be reduced to acting the role of educator. Parker's important insights, in his discussion of the courage required to teach, nevertheless do not incorporate the role of student vulnerability into the process of learning. Weimer (2002, p 26) states that educators 'are motivated to control because teaching makes us vulnerable'. Previous commentators have noted the potential fragility of the learning environment that students may encounter, and the ensuing uncertainty that may be introduced into their learning experiences (Barnett and Coate, 2005).

However, less attention has been paid to the benefits of purposefully introducing uncertainty into the learning environment to increase student vulnerability as a means of achieving good educational outcomes.

According to Baxter Magolda (2004), a fundamental transformation in epistemological, interpersonal, and intrapersonal assumptions is required for each student to develop into an adult capable of self-authorship. It has been my experience that such transformation can be facilitated by a learning environment in which students embrace higher degrees of vulnerability. Under such circumstances, the role of the educator is to lead by example and to demonstrate his or her willingness to be vulnerable to the student body. Thus a pathway to a 'neutral space' is created, a space where mutual respect is developed and friendships grow through which educational processes can be shared. In this neutral space, the students themselves are the teachers and are therefore engaged in the 'highest form of understanding' (Boyer, 1990, p 23). The nature of such interaction is highlighted in the following statements from students:

'Learning is a process of communication, and the communication is not just one way. We should not only get the knowledge from the teacher, but also give the feeling and feedback back to teachers in order to let the teachers know about the status of students and help the future development in teaching.'

'I think that sometime we would like to express our feeling but we do not have the courage to show our feelings, particularly Asian culture. However, it is 
important to express our feeling in a multicultural country like Australia, otherwise people will not understand what we want to do.

'Group sense making assists students uncover feelings and issues and collectively solve problems more efficiently and effectively. It also helps building stronger ties and relations!! The reflection journals are also important in order for the facilitator to shape activities and alter them around how students think and feel about them.'

'I think the reflective journals and group sense making activities encourage students to understand more about their learning potential and take responsibility for what they want to learn. I believe it also builds a great learning relationship between the teacher and student because of the increased communication.'

These comments highlight the willingness of student and educator to learn from each other and to be vulnerable to each other. The presence of vulnerability is a key determinant of the type of personal development required by the programme - the desired outcome being the reasonable adventurer.

\section{The reasonable adventurer}

As previously noted, Heath (1964) defines the reasonable adventurer as a graduate student capable of making his or her own opportunities for satisfaction. Heath alludes to six specific attributes through which students' ability to create opportunities for satisfaction are enhanced:

- Intellectectuality - the ability to alternate between being a believer and a sceptic, to remain curious while determining what matters by making connections between the object under consideration and the real world.

- Close friendships, which bring with them the ability to discover the individuality of others. Students thus realize that they have shared feelings with others and previous perceptions are altered due to these friendships.

- Independence in value judgements - the ability to rely on personal experience rather than external authorities. This increased reliance on one's own judgement provides a route to self-reflection that may be followed with much vigour and enthusiasm.

- Tolerance of ambiguity - the ability to see life as a series of interruptions and recoveries (Dewey, 1922), to be able to suspend judgements until sufficient information has been obtained to make the right decision.

INDUSTRY \& HIGHER EDUCATION June 2009
- Breadth of interest. Heath (1964, p 34) calls this an 'uncommon interest in the commonplace'.

- A sense of humour - a benign but lively sense of humour distinguishes the reasonable adventurer, making him or her good company and capable of sensitivity towards others in conflicting circumstances.

Heath (1964) was thus promoting the idea of a fullyfunctioning graduate, one capable of using his or her individuality in ways that reach well beyond their preexisting mental endowments. Essentially, the person that emerges is anchored in reality and yet capable of finding deep satisfaction in the elements of his or her daily life. As one student expressed it,

'By encouraging people to take risks and make themselves vulnerable, it actually makes it safer to take risks and then you decrease vulnerability. In this sense, you can't push the limits when the limits aren't there to begin with.'

\section{Established reflective practices}

The above discussion does not lay claim to a new way of developing reflective practice. Rather, it seeks to build on (a) past work on reflective practice (for example, Kolb, 1984) and (b) past models of student development (for example, Heath, 1964). However, a key aim of this paper is to show how student reflection can be crafted to facilitate movement between the four stages of Kolb's learning cycle.

Kolb (1984) described knowledge as a by-product of the transformation of experience, arguing that, if students could move productively from concrete experience through reflective observation to abstract conceptualization and then to active experimentation they could enhance learning outcomes. In this paper, a context (the hic et nunc framework), a mechanism (niche construction) and a process (single and group reflection) have been introduced and offered for consideration. The remainder of the paper will assess how these elements collectively enable the 'surfacing' of student awareness, through which improved learning outcomes are achieved. The discussion draws on Kolb's (1984) four stages and learning styles to demonstrate how surfacing occurs. A key assumption in what follows is that individual learners will exhibit strengths and weaknesses across these learning styles (Boud et al, 1985).

\section{Divergence?}

The first phase of Kolb's (1984) learning cycle of learning is from concrete experience to reflective 
observation. This step occurs naturally several times during the semester for each student operating within the hic et nunc framework. During this phase, students must use their imagination and be aware of meanings and values through an orientation towards people and feelings (Evans et al, 1998): this is achieved by means of the reflective processes used in the hic et nunc framework.

Students are asked to consider their personal feelings and to compare those feelings with those of other members of their group. As they do this, the students contemplate their experiences from various perspectives. The development of the second attribute of the reasonable adventurer (close friendships) also aids progress at this stage. My own observations have confirmed the relationship between individual traits, learning styles and natural roles in group work. The phlegmatic student tends to have the greatest capacity for working with others to find meaning and incorporate and truly appreciate feedback.

\section{Assimilation?}

Students with a dual choleric-melancholic orientation naturally act as assimilators, moving the process from one of reflective observation to abstract conceptualization. The capacity to use inductive reasoning to create theoretical models (derived from observations) fits with their general approach to learning. Thus, movement is continued from observing to thinking through a logical and deliberate process. During the group sense making process, such students will typically consult a peer (during phase 3 ) whose opinion they respect for its technical soundness.

\section{Convergence?}

The judgement required to implement ideas in practice is naturally associated with those melancholy-oriented students guided by facts and intent on incremental gains. Through group interaction, their talents are encouraged and supported by others.

\section{Accommodation?}

The final step of Kolb's (1984) cycle of learning is easily completed by those with a sanguine orientation. Their hands-on approach enables then to capitalize on the efforts of fellow group members. They are likely to instil in the group the confidence to take creative risks.

\section{Summary}

It should not be taken from the above discussion that only certain types of student can navigate the steps of the learning cycle. What is suggested is that the interaction among group members in the hic et nunc framework advances the learning cycle. This happens because the individual traits and capacities of individual students are used to produce an effective and blended approach.

\section{Discussion}

While students can learn as individuals in the learning environment discussed here, interaction with others can enhance learning outcomes considerably. The increasing student diversity in higher education (Biggs, 2003) provides educators with a unique opportunity. Building on past research that has highlighted the relationship between superior learning outcomes and higher levels of student diversity (Gurin, 1999), the hic et nunc approach deliberately uses student diversity to produce positive effects.

\section{Student diversity}

In the hic et nunc framework, student diversity is more than a construct of social and ethnic origins. An index of student similarity has been developed to identify the level of diversity in a single class (and between classes). The index is expressed simply as $X / N$, where $X$ is the number of traits common to two students and $N$ is the total number of traits occurring in either. Thus student similarity equals one when two students are identical, and zero when they share no traits. In this approach, eight traits are employed in three separate categories: (a) the student's background (for example, age, origin and area of study); (b) the student's current situation (for example, work commitments, effort committed to study and personal aspirations); and (c) the student's approach to learning (learning style and personality).

Typically, a level of diversity between $45 \%$ and $48 \%$ has been observed for both undergraduate and postgraduate classes. Thus the educator is able to construct a diversity profile for each class and compare different classes. Importantly, the students are informed of the nature of the diversity in the room and this recognition forms an important part of their preparation for the reflection exercises.

\section{Surfacing the learning}

Rather than be hampered by student diversity or aim to lessen the differences among students, the hic et nunc framework exploits those differences to achieve better learning outcomes. Instead of trying to orchestrate a cultural and/or intellectual sea-change (Clanchy and Ballard, 1997) to align student approaches to learning, a divergent learning approach is encouraged. Each student is encouraged to learn in his or her own here and now and to share feelings, attitudes and interpretations of theory with colleagues. 
The six attributes of the reasonable adventurer are developed as the students become mindful and respectful of each other and have enough confidence in the learning environment to bring their feelings to the surface and to share them with others, along with their attitudes and interpretations. Importantly, they expose themselves to multiple forms of feedback and assessment, facilitating an evolutionary processes in which those behaviours that add value are retained and those that do not are replaced with experimental or copied behaviours.

A fundamental element of this evolutionary development is the courage and willingness of the students to reflect honestly, to allow this process to become public at certain times and to embrace uncertainty. The following quotations from students confirm this:

'I feel stress and anxiety of not knowing what's going to happen and in the game for example the outcome depends on how everybody else is playing. In real life, not knowing everything is always present and by forcing me to reflect upon this has made me more open to the thought of that it is OK to not always know these things and it is not always a sign of weakness.'

'Overall whenever there has been uncomfortableness surrounding the presentations, meetings and team work, I have found that it has actually helped. Odd really, as I didn't think it would, but it has, and it seems to make me more eager to get on with it too. I do hope that the whole team feel good about the process, for me a big part of working in a team is about knowing that everyone is happy and wanting to contribute. In the end being out of my comfort zone has done me good and made me more willing to participate.'

'I felt very uncomfortable giving presentations and I still do to some extent. Presentations are now getting to the stage were other class members are very confident and come up with such good ideas it is hard to keep up. I still feel that the format of giving presentations is a great way to learn because it forces people to know the topic before teaching it to others.'

\section{Implications for the educator}

The starting point for the discussion in this paper was the assumption that what students must learn relates primarily to what resides inside them - that, for the teacher, it is better to be the 'guide on the side' than the 'sage on the stage'. While the hic et nunc framework has been developed specifically for the context of enterprise education, many of the ideas are transferable to other settings.

INDUSTRY \& HIGHER EDUCATION June 2009
The group sense making method was adapted from a process originally developed for nursing education (Hart et al, 1998) and is potentially useful for any educator seeking to facilitate deep reflective practice in support of a process of self-discovery that can lead to incremental gains in each study period. The curriculum can be designed to stretch students throughout the study period, as they develop the capacity to adjust their desired learning outcomes.

Perhaps the most interesting contribution of the approach described here is its synthesis of several factors to create a learning environment in which genuine and beneficial reflection can occur regularly. Developed from the ideas of Whitehead (1929) and Tyler (1949), the hic et nunc framework deliberately seeks to use identifiable student diversity as an active ingredient in student reflection. Because of the trust (or willingness to be vulnerable) present in the learning environment, students use their individuality to make sense of their progress. They allow 'inner secrets' to be surfaced and this typically emboldens them, providing a foundation of inner confidence.

The role of the educator becomes clearer as the process continues. It is essential to ensure speedy and supportive feedback to students so that they can consider their position and adapt their habits of thought as they see fit. Along the way, debriefings on how the cohorts are progressing help those feeling uncomfortable to make sense of the process. The result is that it becomes possible for the students to learn what they most need to learn about their own entrepreneurial capacity.

\section{Conclusion}

It has been argued here that, by allowing students to 'surface' their reflections, a deeper level of reflective behaviour is possible. A reflective journal does not need to remain a useful secret between student and educator: group sense making can aid the development of the individual student and the functioning of study groups. The students' views that have been cited in the paper provide evidence that the hic et nunc framework can enable students to learn about their entrepreneurial capabilities by learning about themselves.

The specific educational setting in this case should not preclude any of the processes discussed from being applied to other disciplines study. The key to their use is the willingness of the educator to incorporate the student's development into the essential learning outcomes of the programme in question. A framework that enables students to bring their feelings to the surface and reflect repeatedly on their fitness vis-à-vis the learning environment is applicable to all forms of experiential learning. 


\section{References}

Barnett, R., and Coate, K. (2005), Engaging the Curriculum in Higher Education, Society for Research into Higher Education and Open University Press, Maidenhead.

Baxter Magolda, M. (2004), Making Their Own Way, Stylus, Sterling, VA

Biggs, J. (2003), Teaching for Quality Learning at University, Society for Research into Higher Education and Open University Press, Buckingham.

Boud, D., Rosemary, K., and Walker, D. (1985), Reflection: Turning Experience into Learning, Kogan Page, New York.

Boyer, E. (1990), Scholarship Reconsidered: Priorities of the Professoriate, Jossey-Bass, San Francisco, CA.

Clanchy, J., and Ballard, B. (1995), 'Generic skills in the context of higher education', Higher Education Research \& Development, Vol 14, No 2, pp 155-166.

Dewey, J. (1922), Human Nature and Conduct: an Introduction to Social Psychology, Henry Holt and Company, New York.

Evans, N., Forney, D., and Guido-DiBrito, F. (1998), Student Development in College, Jossey-Bass, San Francisco, CA

Gurin, P. (1999), 'New research on the benefits of diversity in college and beyond: an empirical analysis', Diversity Digest, Spring, www.diversityweb.org/Digest/Sp99/benefits.html
Hart G., Clinton M., Nash R., Barnard A., Collins D., Gaskill D., Harris M., Yates P., and Mitchell M. (1998), Stories from Experience: Monograph of Practice /ncidents, Queensland University of Technology, Brisbane.

Heath, R. (1964), The Reasonable Adventurer, University of Pittsburgh Press, Pittsburgh, PA.

Jones, C. (2007), 'Contemplating Whitehead's freedom and discipline', Journal of University Teaching and Learning Practice, Vol 4, No 1, pp 1-12.

Kolb, D.A. (1984), Experiential Learning: Experience as the Source of Learning and Development, Prentice-Hall, Englewood Cliffs, NJ.

Odling-Smee, F.J., Laland, K.N., and Feldman, M.W. (2003), Niche Construction: the Neglected Process in Evolution, Princeton University Press, Princeton, NJ.

Parker, P.J. (1997), The Courage to Teach: Exploring the Inner Landscape of a Teacher's Life, Jossey-Bass, San Francisco, CA.

Pianka, E. (1973), 'The structure of lizard communities', Annual Review of Ecology and Systematics, Vol. 4, pp 53-74.

Tyler, R.W. (1949), Basic Principles of Curriculum and Instruction, University of Chicago Press, Chicago, IL. Weimer, M. (2002), Learner-Centred Teaching: Five Key Changes to Practice, Jossey-Bass, San Francisco, CA

Whitehead, A.F. (1929), The Aims of Education and Other Essays, The Free Press, New York. 